\title{
A COMPARAÇÃO ENTRE GRUPOS OCUPACIONAIS E LOTAÇÃO SETORIAL/DEPARTAMENTAL DE UMA IFES SOB A ÓTICA DA SOCIALIZAÇÃO ORGANIZACIONAL
}

\section{COMPARISON OF OCCUPATIONAL GROUPS AND CAPACITY SECTORIAL / DEPARTMENT OF IFES UNDER THE OPTICS OF ORGANIZATIONAL SOCIALIZATION}

Diego César Terra de Andrade Instituto Federal de Educação, Ciência e Tecnologia do Sul de Minas Gerais IF SUL DE MINAS diego.terra@ifsuldeminas.edu.br

Heidy Rodrigues Ramos Universidade Nove de Julho - SP UNINOVE heidyr@gmail.com

Submissão: $12 / 11 / 2014$ Aprovação: 27/05/2015 


\title{
RESUMO
}

Esta pesquisa foi realizada com servidores técnico-administrativos e docentes de uma IFES, objetivando avaliar se há entre estes grupos ocupacionais diferença no nível de socialização organizacional e observar se o nível de socialização organizacional varia quanto à lotação setorial/departamental. A fundamentação baseia-se no enfoque dos Conteúdos e da Informação. Com relação à comparação dos grupos ocupacionais docentes e técnicos administrativos, não se observou diferenças significativas nos fatores hipotéticos, à exceção do fator Linguagem e Tradição. Finalmente, ao observar se há variação quanto à lotação setorial/departamental, não foi possível chegar a uma conclusão devido à heterogeneidade dos resultados do dendograma.

Palavras-chave: Administração pública; Gestão de pessoas; REUNI; IFES; Socialização Organizacional.

\begin{abstract}
This research was conducted with technical and administrative staff and faculty of an university, to evaluate whether there is among these occupational groups difference in organizational socialization level and see if the level of organizational socialization varies as the sectoral / departmental capacity. The rationale is based on the approach of Content and Information. The comparison of teachers and administrative staff occupational groups, there was no significant differences in hypothetical factors, except for the Language and Tradition factor. Finally, to see if there is variation in the sectoral / departmental capacity, we could not reach a conclusion because of the heterogeneity of dendogram results.
\end{abstract}

Keywords: Public administration; Human resources; REUNI; IFES; Organizational socialization. 


\section{INTRODUÇÃO}

Nas últimas décadas, observa-se que a sociedade vem passando por inúmeras transformações decorrentes de um novo contexto econômico, político e social. Nesse mesmo sentido, o setor público vem sendo obrigado a repensar sua forma de agir, buscando um modelo de gestão eficiente (BRESSER-PEREIRA, 2001; MARINI, 2002; MARTINS, 1997; MENDES; TEIXEIRA, 2000). Contudo, algumas especificidades, advindas de sua própria natureza, o diferem, em muito, de outros setores. Entre essas divergências, a finalidade, os meios utilizados para recrutamento, seleção e contratação, as políticas de remuneração, os métodos de avaliação de desempenho, entre outros, podem ser citados.

Dessa forma, quando se fala em Gestão de Pessoas no setor público, faz-se necessário atentar para uma realidade diversa daquela já consagrada nas organizações privadas. De maneira geral, por exemplo, quando uma empresa do segundo setor seleciona uma pessoa para fazer parte do seu quadro de funcionários, espera-se que ela consiga contribuir para aumentar os lucros da empresa. Por sua vez, quando uma organização do setor público realiza um concurso e empossa um novo servidor, ela espera que ele consiga aumentar os índices de eficiência, eficácia e efetividade, o que não necessariamente corresponde a lucro, e sim a uma melhor prestação de serviços à sociedade.

Nesse sentido, Oliveira et al. (2008) atentam que, no setor público, tal ênfase ganha uma conotação ética de preocupação com a aplicação de recursos públicos e a melhoria da prestação de serviços ao cidadão. Diante disso, Borges et al. (2010) afirmam que uma das respostas da Academia para tentar sanar tal problema foi intensificar as pesquisas sobre socialização organizacional, como uma ferramenta capaz de auxiliar a Gestão de Pessoas.

Dá-se o nome de socialização organizacional, de acordo com Shinyashiki (2003), a maneira como a organização recebe os funcionários e os integram à sua cultura, seu contexto e sistema, para que eles possam comportar-se de maneira adequada às expectativas da organização. Já Schein (1982) observa que o uso do termo socialização organizacional pode estar associado ao processo no qual um novo membro aprende os sistemas de valores, as normas e os padrões de comportamento demandados por uma organização ou pelo grupo no qual está ingressando. Motta (1993) afirma ainda que a socialização organizacional é um processo contínuo que se inicia antes mesmo da entrada do indivíduo na empresa e continua durante toda a sua permanência na organização (MOTTA, 1993).

Dessa forma, observa-se a relevância de análises organizacionais no que tange à questão da socialização, no atual cenário da educação superior brasileira, uma vez que autores como Andrade et al. (2011) apontam mudanças significativas nas Instituições Federais de Ensino Superior (IFES) a partir de 24 de abril de 2007, quando foi lançado, pelo Governo Federal, o Plano de Desenvolvimento da Educação (PDE), que contém cerca de quatro dezenas de medidas, entre elas o Decreto $n^{\circ}$. 6.096, que institui o Programa de Apoio a Planos de Reestruturação e Expansão das Universidades Federais (REUNI) (BRASIL, 2009a).

Para ilustrar o quanto o REUNI está sendo impactante na IFES objeto do estudo deste trabalho, verificou-se que em 2006 ela ofertava 620 vagas, saltando em 2011 para 1480 novas matrículas anuais. E, como consequência do aumento do número de vagas ofertadas aos alunos cresce o número de docentes e técnicos administrativos. 
Frente a este crescimento percebe-se um aumento nos problemas de gestão de pessoas, comentadas no dia-a-dia da Instituição, tais como a diferença de desempenho entre setores, centros e servidores. Assim, questões desta ordem justificam a realização desta pesquisa.

Por tanto, tem-se a seguinte questão: como se encontra o processo de socialização organizacional nesta instituição, segundo os grupos ocupacionais docentes e técnicoadministrativos? Desta forma este trabalho possui os seguintes objetivos:

a. Avaliar se há entre estes grupos ocupacionais diferença no nível de socialização organizacional;

b. Observar se o nível de socialização organizacional varia quanto à lotação setorial/departamental.

Para tanto foi utilizado o Inventário de Socialização Organizacional composto de 45 perguntas, divididas em sete fatores, e que, por ora, fora validado ao setor público brasileiro, conforme afirmam Borges et al. (2010). E, ainda, segundo a mesma autora, "esta versão do questionário é melhor do que aquela disponível anteriormente" (BORGES et al., 2010, p. 27), já aplicada em trabalho realizado na Universidade federal do Rio Grande do Norte (OLIVEIRA. et al., 2008), pois sua capacidade de explicação fatorial é superior.

\section{SOCIALIZAÇÃO ORGANIZACIONAL}

Sob o ponto de vista sociológico, a socialização é um processo contínuo no qual o indivíduo ao longo da vida aprende, identifica hábitos e valores característicos que o ajudam no desenvolvimento de sua personalidade e na integração ao seu grupo, tornando-o sociável. Trazendo-lhes hábitos e valores que não lhes são inatos. Segundo Levy Junior (1973, p. 60), "em estado de isolamento social, o indivíduo não é capaz de desenvolver um comportamento humano, pois esse deve ser aprendido ao longo de suas interações com os grupos sociais". Nesse sentido, Chanlat et al. (1996, p. 36) afirmam que "o ser humano não vive em um círculo fechado, pois é na relação com o outro que o ego se constrói”.

Durkheim (1987) ressalta a importância da socialização ao mostrar que a sociedade só pode existir porque penetra no interior do ser humano, moldando sua vida, criando sua consciência, suas ideias e valores. Socializar-se implica o desenvolvimento de uma identidade diferenciadora, ao mesmo tempo em que a inclusão sócia histórica ao meio (construído) assemelha-se e identifica-se com os grupos de referência (BERGER; BERGER, 1977; BERGER; LUCKMANN, 2002, 2004; MARTIN-BARÓ, 1992; TORREGROSA; VILLANUEVA, 1984). Tal processo, portanto, é dinâmico no sentido de que é contínuo e encerra a vivência de contradições existenciais. É um processo que se desenrola durante toda a vida do indivíduo (BORGES et al., 2010), ou seja, não é possível afirmar que ele possua um início, meio e fim.

Sob uma abordagem psicológica, e laboral, segundo Gontijo e Melo (2005) a socialização organizacional é tida como um processo de complexa descrição e condução, sobretudo pelo fato de envolver muitos elementos subjetivos, com implicações não apenas na vida profissional e educacional, como também em aspectos afetivos do indivíduo. Mesmo assim, o tema vem despertando o interesse de administradores, pesquisadores e outros profissionais há algum tempo (FELDMAN, 1976; SHINYASHIKI, 2000). 
De acordo com Shinyashiki (2003), dá-se o nome de socialização organizacional à maneira como a organização recebe os funcionários e os integram à sua cultura, seu contexto e sistema, para que eles possam comportar-se de maneira adequada às expectativas da organização. Para Schein (1982), o uso do termo pode estar associado ao processo no qual um novo membro aprende os sistemas de valores, as normas e os padrões de comportamento demandados por uma organização ou pelo grupo no qual está ingressando.

Conforme expõe Shinyashiki (2003), os indivíduos passam por processos de socialização durante todas as etapas de sua vida, internalizando padrões de comportamento, normas e valores decorrentes do contex to no qual se encontram inseridos ou da situação social na qual estão vinculados. Trata-se de um processo contínuo que se inicia antes mesmo da entrada do indivíduo na empresa e continua durante toda a sua permanência na organização (MOTTA, 1993). Sendo assim, Oliveira et al. (2008a) classificam o processo de socialização organizacional em bidirecional e recíproco; primeiro porque a adaptação é mútua, tendo em vista a busca de uma verdadeira simbiose entre as partes (organização/funcionário), e segundo porque cada parte atua sobre a outra.

Conforme revisão bibliográfica realizada por Borges e Albuquerque (2014), cronologicamente, os estudos sobre socialização organizacional evoluíram sob quatro correntes distintas:

a. Táticas Organizacionais - a atenção centra-se nas ações da organização, que visam facilitar o processo de socialização dos indivíduos.

b. Desenvolvimentista - o foco se encontra nos processos cognitivos que os sujeitos da organizacional vivenciam, de maneira a analisar as nuanças e ambiguidades da socialização e sua forma sequencial durante a vida laboral do trabalhador.

c. Conteúdos e da Informação - a atenção se volta aos processos cognitivos do indivíduo, relacionando-os aos conteúdos do processo de socialização e ao papel da busca (pró) ativa de informações, abandonando a suposição de estágios sequenciais.

d. Tendências integradoras - esta corrente integra as anteriores de forma tal a complementá-las, considerando as diferentes variáveis para se ter uma compreensão mais ampla do fenômeno.

Ademais, em virtude dos objetivos desta pesquisa (já mencionados), cabe ênfase, aqui, ao enfoque dos conteúdos e da informação, pois, como exposto por Borges et al. (2010), o Inventário de Socialização Organizacional utilizado neste trabalho pertence a este enfoque.

\subsection{ENFOQUE DOS CONTEÚDOS E DA INFORMAÇÃO}

De acordo com Borges et al. (2010), nesta corrente, a atenção se volta aos processos cognitivos do indivíduo, relacionando-os aos conteúdos do processo de socialização e ao papel da busca (pró) ativa de informações, abandonando a suposição de estágios sequenciais.

Oliveira et al. (2008) afirmam que as pesquisas sob esse enfoque consideram a proatividade dos indivíduos, entendendo que os iniciantes em uma organização são agentes ativos que buscam as pessoas e os locais de aprendizado, julgados como valiosos para facilitar 
o próprio ajustamento, sendo capazes de influenciar as normas do grupo e os resultados de desempenho. Já com relação ao conteúdo e informação, as autoras afirmam que, de acordo com Ashforth et al. (2007), consiste em um conjunto de aspectos relacionados ao trabalho, os quais são considerados essenciais ao aprendizado de um indivíduo, para que esse possa se tornar um membro proficiente e se sentir confortável na organização. Ashforth et al. (2007) expõem que existe um conjunto de aspectos relacionados ao trabalho que são considerados essenciais ao aprendizado do funcionário, para que ele possa se tornar um membro capaz e, assim, se sinta adaptado à organização.

Nesse sentido, Carvalho (2009) afirma que o domínio das tarefas envolve fatores, como deveres e obrigações, responsabilidades, prioridades, modo de usar equipamentos e de lidar com questões de rotina. Os papéis de trabalho focam os limites da autoridade e da responsabilidade, as expectativas e os comportamentos adequados ao posto. Os processos de grupo referem-se à interação com os colegas, às normas e valores do grupo e à estrutura normativa do grupo de trabalho. Por fim, os atributos organizacionais dizem respeito às políticas, ao poder, ao conjunto de valores do sistema organizacional, à missão e ao estilo de liderança. Segundo a mesma autora, os resultados do estudo encampados sob esse enfoque indicaram, ainda, que a aquisição de informações sobre o domínio da tarefa, dos papéis e dos processos de grupo tende a ser mais importante durante as experiências iniciais no emprego do que a aquisição de informações relacionadas aos atributos organizacionais.

Oliveira et al. (2008) afirmam que algumas das tipologias, nessa corrente, incluíram escalas para mensurar a aquisição de conteúdo. Carvalho (2009) cita alguns exemplos de trabalhos que incluem essas escalas, tais como:

a. Ostroff e Kozlowski (1992), que apresentaram uma medida de socialização organizacional que envolve quatro domínios de conteúdo: tarefas do emprego, papéis de trabalho, processos de grupo e atributos organizacionais.

b. Morrison (1995), para construir sua escala, integrou várias tipologias para derivar sete domínios de conteúdo (informação técnica sobre como executar as tarefas; informação de atribuições sobre as requisições e expectativas do papel de trabalho; informação social sobre outras pessoas e os relacionamentos com elas; informação avaliativa sobre como o desempenho e o comportamento estão sendo apreciados por outros na organização; informação normativa sobre a cultura organizacional; informação organizacional sobre a estrutura, procedimentos, produtos/serviços e resultados da empresa; e informação política sobre a distribuição de poder dentro da organização).

c. Taormina (1997) apresenta um modelo de socialização organizacional como um processo contínuo envolvendo quatro domínios, os quais, por sua vez, incluem quatro áreas de conteúdo que operam de forma contínua e interativa umas com as outras (treinamento; entendimento; suporte proporcionado por colegas de trabalho; e perspectivas de futuro).

d. Haueter, Macan e Winter (2003) propõem a escala de três dimensões, a saber: organização, grupo e tarefa. 
Ademais, segundo Carvalho (2009), um dos mais conhecidos trabalhos sob esta corrente e tipologia é o de Chao et al. (1994). Esse autor defende a existência de seis domínios de conteúdo da socialização organizacional (Quadro 1).

Quadro 1 Domínios de conteúdo da socialização organizacional

\begin{tabular}{|l|l|}
\hline $\begin{array}{l}\text { Proficiência de } \\
\text { desempenho }\end{array}$ & Avalia a extensão nas quais os indivíduos dominam suas tarefas. \\
\hline Pessoas & Envolve a satisfação nas relações com membros da organização. \\
\hline Políticas & $\begin{array}{l}\text { Abrange o sucesso de um indivíduo em obter informações com respeito às } \\
\text { relações de trabalho formais e informais e às estruturas de poder dentro da } \\
\text { organização. }\end{array}$ \\
\hline História & $\begin{array}{l}\text { Diz respeito ao conhecimento das tradições, costumes, mitos e rituais que } \\
\text { compõem a cultura da organização. }\end{array}$ \\
\hline Linguagem & $\begin{array}{l}\text { Aborda o conhecimento do indivíduo sobre a linguagem técnica profissional, } \\
\text { bem como a familiaridade com a linguagem informal da organização. }\end{array}$ \\
\hline $\begin{array}{l}\text { Objetivos e valores } \\
\text { organizacionais }\end{array}$ & $\begin{array}{l}\text { Compreende a interiorização das regras ou princípios que mantêm a } \\
\text { integridade da organização. }\end{array}$ \\
\hline
\end{tabular}

Fonte: adaptado de Chao et al. (1994)

Oliveira et al. (2008) explicam ainda que Chao et al. (1994), em seus estudos, observaram também que, normalmente, as pessoas bem socializadas em seus papéis organizacionais têm maiores rendimentos pessoais, são mais satisfeitas, mais envolvidas com suas carreiras, mais adaptáveis e têm um melhor senso de identidade pessoal, comparativamente às menos socializadas.

\section{CONTEXTO E RELEVANCIA DA PESQUISA}

No Brasil, no segundo semestre de 2006, inicia-se uma campanha contra o atual formato do ensino ministrado na maioria das universidades, com diagnósticos e análises variados, baseados em dados estatísticos das vagas nas universidades públicas e das altas taxas de evasão no ensino superior. A proposta apresentada para se contrapor a esse quadro teve, na ocasião, como principal interlocutor o reitor da Universidade Federal da Bahia (UFBA), professor Naomar Monteiro de Almeida Filho, que, em inúmeras visitas, aulas inaugurais e palestras, divulgou a chamada "Universidade Nova" como a solução contra a obsolescência das universidades de modelo tradicional (LÉDA; MANCEBO, 2009).

Em apresentação no seminário intitulado "Universidade Nova: Reestruturação da Arquitetura Acadêmica da UFBA", o Professor Naomar, afirma que:

[...] a ideia de estudos superiores de graduação de maior amplitude e não comprometida com uma profissionalização precoce e fechada, bem como maior integração entre esses estudos e os de pós-graduação, já é realidade em muitos países social e economicamente desenvolvidos. O processo europeu de Bolonha é um exemplo eloquente dessa concepção acadêmica que, por força das demandas da Sociedade do Conhecimento e de um mundo do trabalho marcado pela desregulamentação, 
flexibilidade e imprevisibilidade, certamente se consolidará como um dos modelos de educação superior de referência para o futuro próximo [...] (UNIVERSIDADE FEDERAL DA BAHIA - UFBA, 2007, p. 17).

Por tanto, conclui-se que a proposta denominada "Universidade Nova" possui evidente similaridade com processo europeu, denominado Declaração de Bolonha. No Brasil, de acordo com Léda e Mancebo (2009), a possibilidade de materialização desse modelo, em âmbito nacional, vem com a publicação do Decreto $n^{\circ}$. 6.096. Seu artigo $1^{\text {o }}$ define o objetivo do REUNI:

Art. $1^{\circ}$ Fica instituído o Programa de Apoio a Planos de Reestruturação e Expansão das Universidades Federais REUNI, com o objetivo de criar condições para a ampliação do acesso e permanência na educação superior, no nível de graduação, pelo melhor aproveitamento da estrutura física e de recursos humanos existentes nas universidades federais (BRASIL, 2009a, p. 1).

São metas e diretrizes gerais do Programa:

a. Aumentar a qualidade do ensino por meio da inovação e adequação acadêmicas com a articulação entre graduação, pós-graduação e educação básica, profissional e tecnológica;

b. Elevar, de forma gradual, a taxa de conclusão média dos cursos de graduação presenciais para $90 \%$ e atingir a taxa da relação aluno/professor em cursos presenciais de graduação igual a 18;

c. Aumentar em pelo menos $20 \%$ as matrículas nos cursos de graduação;

d. Prazo de cinco anos, a contar do início de cada plano, para o cumprimento das metas estabelecidas pelas instituições federais de ensino superior.

O Artigo $5^{\circ}$ diz que: “O ingresso no Programa poderá ser solicitado pela IFES, a qualquer tempo, mediante proposta instruída”, ou seja, sua adesão é facultativa; contudo, como já exposto, as 54 Universidades Federais existentes em 2007 entraram no programa (BRASIL, 2009a), inclusive a Instituição pesquisada.

Relativo, especificamente, aos Recursos Humanos, em julho de 2007, a Instituição Federal de Ensino Superior Pesquisada (IFESP)', no período imediatamente posterior à sua adesão ao programa do Decreto $\mathrm{n}^{\circ}$. 6.096, contabilizava em seu quadro de servidores, 356 professores e 237 servidores técnico-administrativos, sendo 59 com nível superior $(24,89 \%)$ e os demais de nível intermediário ou auxiliar (IFESP, 2011).

A partir de 2008, novos servidores, docentes e servidores técnico-administrativos, foram empossados, conforme Quadro 2. Contudo, cabe ressaltar que algumas dessas contratações são frutos de reposição de pessoal (banco de equivalentes), principalmente aposentadorias. 
Quadro 2 Contratações de servidores técnico-administrativos e docentes a partir de 2008

\begin{tabular}{|c|c|c|c|}
\hline Ano/Servidor & $\begin{array}{c}\text { Técnico Administrativo } \\
\text { Nível D }\end{array}$ & $\begin{array}{c}\text { Técnico Administrativo - } \\
\text { Nível E }\end{array}$ & Docentes \\
\hline $\mathbf{2 0 0 8}$ & 14 & 10 & 20 \\
\hline $\mathbf{2 0 0 9}$ & 16 & 15 & 53 \\
\hline $\mathbf{2 0 1 0}$ & 15 & 15 & 61 \\
\hline $\mathbf{2 0 1 1}$ & 45 & - & 62 \\
\hline $\mathbf{2 0 1 2}$ & 39 & - & 29 \\
\hline Total & $\mathbf{1 2 9}$ & $\mathbf{4 0}$ & $\mathbf{2 2 5}$ \\
\hline
\end{tabular}

Fonte: dados fornecidos pelo departamento de Gestão de Pessoas da IFESP (2011)

Este aumento no quadro de servidores fornece suporte a expansão do número de vagas oferecidas nos cursos da IFESP, que em 2006 eram de 620 vagas, e que em 2011, já é da ordem de 1480 novas matriculas (Gráfico 1).

Gráfico 1 Evolução das vagas de ingresso nos processos seletivos da IFES pesquisada de 2007 a 2011

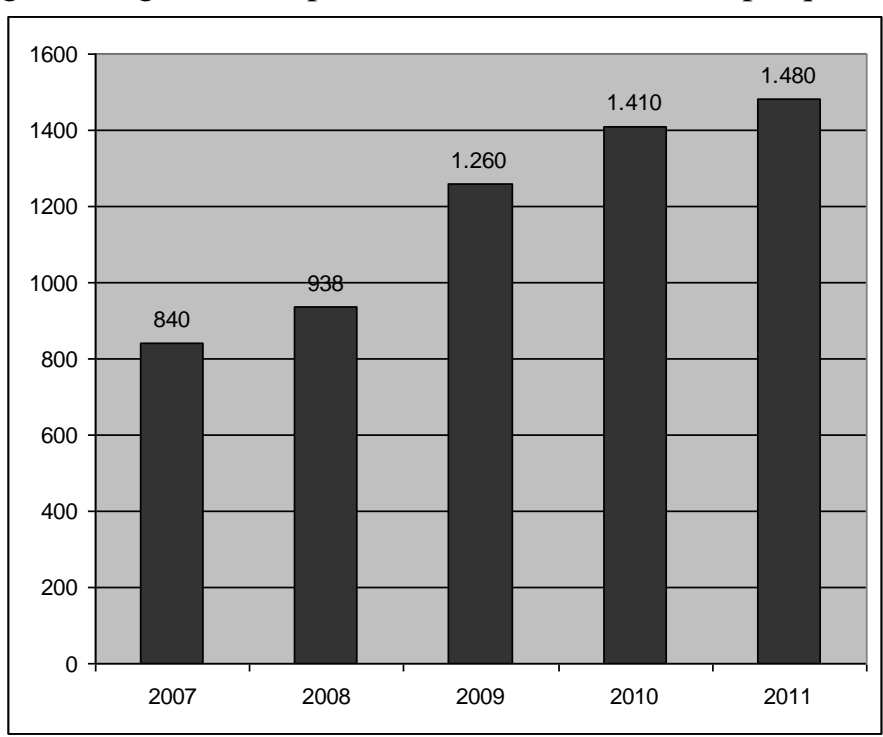

Fonte: IFESP (2011)

Segundo dados obtidos em material de divulgação da IFESP, essa expansão vem sendo acompanhada de modificações estruturais e pedagógicas, para assim serem sustentadas (IFESP, 2011), como exemplo, a construção de prédios, pavilhões de aulas, laboratórios, centros de convivência estudantil, reformulações das diretrizes e planos de cursos, entre outras. Conclui-se, a partir de tais observações e frente ao histórico de expansão da IFESP, que o momento atual é sem precedentes em sua história.

\section{PROCEDIMENTOS METODOLÓGICOS}

Mediante os objetivos e questão de pesquisa deste estudo, do ponto de vista da abordagem, optou-se por realizar uma pesquisa quantitativa, com finalidade descritiva, utilizando para o levantamento um questionário estruturado do tipo survey, conforme descrito por Cervo e Bervian (1996), Lakatos e Marconi (1995) e Mattar (1999). 
A Universidade, objeto do estudo, é uma instituição de ensino com mais de um século de existência, localizada no interior de Minas Gerais, fundada no início do século dezenove por missionários americanos. Tornou-se, no ano de 1938, escola superior; foi federalizada em 1963 e manteve sua vocação voltada ao ensino das Ciências Agrárias. Em 1994, a IFESP tornou-se uma Universidade Federal. A população da pesquisa é composta por 815 elementos. Esses elementos são servidores, na ativa e concursados, da Instituição Federal de Ensino Superior Pesquisada (IFESP). Desse universo, têm-se os servidores técnico-administrativos, distribuídos na seguinte classificação (Quadro 3):

Quadro 3 Nível de classificação dos técnicos administrativos

\begin{tabular}{|c|c|c|}
\hline Nível de Classificação & Quantidade & Percentual \\
\hline E & 106 & $30,54 \%$ \\
\hline D & 172 & $49,56 \%$ \\
\hline C & 60 & $17,29 \%$ \\
\hline B & 6 & $1,72 \%$ \\
\hline A & 3 & 0,86 \\
\hline TOTAL & $\mathbf{3 4 7}$ & $\mathbf{1 0 0 \%}$ \\
\hline
\end{tabular}

Fonte: dados fornecidos pelo departamento de Gestão de Pessoas da IFESP (2011)

Os 468 elementos restantes da pesquisa são docentes. Estes estão divididos de acordo com a seguinte classe (Quadro 4):

Quadro 4 Classe dos Docentes

\begin{tabular}{|c|c|c|}
\hline Classe & Quantidade & Percentual \\
\hline Professor Adjunto & 234 & $50,00 \%$ \\
\hline Professor Assistente & 27 & $5,77 \%$ \\
\hline Professor Associado & 143 & $30,56 \%$ \\
\hline $\begin{array}{c}\text { Professor do Ensino Básico, Técnico e Tecnológico } \\
\text { (EBTT) }\end{array}$ & 9 & $1,92 \%$ \\
\hline Professor Titular & 55 & $11,75 \%$ \\
\hline TOTAL & $\mathbf{4 6 8}$ & $\mathbf{1 0 0 , 0 0 \%}$ \\
\hline
\end{tabular}

Fonte: dados fornecidos pelo departamento de Gestão de Pessoas da IFESP (2011)

Optou-se pela amostragem intencional por considerá-la mais adequada ao propósito da pesquisa, uma vez que os atos de provimento não param. Assim, necessitou-se estipular um limite de tempo na amostra. Sendo esse tempo à data do efetivo exercício do servidor ter ocorrido até 31 de dezembro de 2010. Para isso, utilizou-se questionário estruturado, com 815 membros da população, objeto da pesquisa.

Já quanto ao tamanho da amostra, levaram-se em consideração os valores estimados para $\mathrm{p}=0,5$ e Intervalo de Confiança (IC) de 95\%, considerando o Fator de Correção para Populações Finitas, calculado pela fórmula $(\mathrm{N}-\mathrm{n}) / \mathrm{N}$, em que N é o tamanho da população, e n, o tamanho da amostra (COCHRAN, 1965). Seguindo esses parâmetros, o número mínimo de respostas exigido para a população de 815 servidores é de 261 participações.

Quanto ao instrumento de pesquisa, utilizaram-se o questionário do Inventário de Socialização Organizacional, que, como já elucidado e de acordo com Borges et al. (2010), é 
baseado na pesquisa de autoria de Chao et al. (1994). Sendo que, desta pesquisa, uma primeira versão fora adaptada, no Brasil, de uma amostra de trabalhadores da construção civil e de uma rede de supermercados, por Borges, Ros e Tamayo, no ano de 2001 (BORGES et al., 2010). Em 2005, Borges, em trabalho não publicado, redigiu novamente os itens do Inventário, adaptando-o à linguagem cotidiana dos participantes. Para levantar o linguajar típico, a autora utilizou a fala de servidores da UFRN em entrevistas concedidas por 12 servidores (BORGES et al., 2010). A próxima etapa foi à realização de um teste com especialistas (seis participantes) por meio do qual avaliou-se a adequação dos itens para a mensuração dos fatores hipotéticos (GÜNTHER, 1999; PASQUALI, 1997, 1999 apud BORGES et al., 2010). Desses participantes, três eram professores do Departamento de Psicologia, da área de Psicologia Social da UFRN, e três eram professores da Universidade Complutense de Madrid. Ainda, segundo as autoras, tal teste foi importante para o aperfeiçoamento da redação dos vários itens e eliminação de outros tantos.

Os itens eliminados foram os que maiores divergências, entre os participantes, apresentaram. Quando as divergências eram mais localizadas, ou seja, em um ou dois dos participantes, a autora trabalhou no aperfeiçoamento dos itens. Por fim, o inventário ficou com 54 itens, dispostos em uma escala tipo Likert, variando de -2 (discordo muito) a +2 (concordo muito). A escala empregada é a mesma utilizada desde a versão estadunidense sugerida por Chao et al. (1994) (BORGES et al., 2010).

Como já comentado, esse questionário de 54 itens foi utilizado pela primeira vez no Brasil, em 2005, por Oliveira et al. (2008), em pesquisa na UFRN. Uma última versão foi apresentada por Borges et al. (2010), que após análises estatísticas, sua adaptação e validação à administração pública brasileira culminaram no ISO, composto de 45 itens e sete fatores hipotéticos, a saber:

a. Acesso a Informações (Políticas) - Acessar informações, saber sobre datas importantes, processos organizacionais, critérios e poder.

b. Competência e Proatividade - Ser apto para criar, ser eficaz, produtivo, ativo para buscar informações.

c. Integração com as Pessoas - Sentir-se aceito pelos outros, incluído na equipe, na organização e participar no processo de tomada de decisão.

d. Não Integração com a Organização - Ausência do domínio da linguagem, do emprego, do conhecimento sobre os processos organizacionais e da cultura organizacional.

e. Qualificação Profissional - Conhecimento e experiência profissional. Domínio da linguagem profissional e tarefas.

f. Objetivos e Valores Organizacionais - Conhecer e identificar-se com objetivos e prioridades organizacionais. Conhecer a história organizacional.

g. Linguagem e Tradição - Dominar a linguagem profissional e organizacional. Conhecer tradições e histórias dos colegas. Saber identificar as pessoas mais influentes.

Cabe ressaltar que, de acordo com Borges et al. (2010), esses fatores apresentaram os coeficientes do alfa de Cronbach $(\alpha)$ entre 0,70 e 0,83 (todos acima do ponto de corte aceito pelo Conselho Federal de Psicologia) e capacidade da variância explicada de 47,68\%. De 
acordo com as autoras, isso indica que essa versão do questionário é melhor do que aquela disponível anteriormente. Portanto, essa foi à versão utilizada no presente trabalho.

Com relação à coleta dos dados, foram utilizados os serviços do programa on-line SurveyMonkey, que é uma ferramenta de criação e distribuição de questionários via web. A coleta das informações necessárias à realização do estudo ocorreu em três etapas, envolvendo os grupos constituintes da amostra do estudo (servidores técnico-administrativos e docentes da IFES, empossados até 31 de dezembro de 2010). Sendo realizada nos dias 12 de abril, 16 de maio e 5 de julho de 2011. Nessas ocasiões, foram encaminhadas mensagens eletrônicas aos endereços de e-mail institucional dos participantes da pesquisa, contendo um link de acesso ao Inventário de Socialização Organizacional.

Para as análises dos dados, as respostas dos participantes foram baixadas do site SurveyMonkey e, em seguida, submetidas às rotinas estatísticas descritivas disponíveis no Software Statistical Package of Social Sciences (SPSS) para Windows versão 17.0.

Como o ISO é uma escala composta por sete fatores (multifatorial), seus resultados foram apurados fator por fator. Assim, se obteve um resultado (ou média fatorial) para cada um dos fatores, ou seja, o diagnóstico da socialização organizacional da IFES foi feito baseando-se nos sete fatores, como já apresentado, pelo trabalho de Borges et al. (2010). Por exemplo, para o Fator 1, Acesso a Informações (Políticas), utilizou-se apenas as respostas dos itens 37, 38, 41, 42 e 47.

Para avaliar se há entre os servidores técnico-administrativos e docentes diferença na percepção do seu nível de socialização organizacional foi utilizado o teste T de Student. Como sugerido por Hair Júnior et al. (2005), o teste T é indicado quando se busca aferir a igualdade entre médias de duas ou mais amostras.

Em busca do segundo objetivo - observar se o nível de socialização dos servidores varia quanto à sua lotação setorial/departamental - foi realizada a análise de Cluster pelo método de Ward, com distância euclidiana quadrada. Segundo Hair Júnior et al. (2005) e Bagozzi, Yi e Philipps (1991), essa análise é utilizada quando se pretende agrupar os respondentes com base na proximidade de suas respostas. Ou seja, divide a população em subpopulações que possuem características homogêneas. É oportuno dizer que o corte Dlink/Dmax será realizado a partir da observação dos resultados, conforme indicado por Hair Júnior et al. (2005). Cabe ressaltar ainda que a instituição adota como critério de segregação, em todos os e-mails institucionais, uma abreviação indicativa do setor/departamento ao qual o servidor é lotado. Como no exemplo hipotético fulano@dae.instituicao.br, em que "fulano" é o nome do servidor; "dae", o nome do departamento, neste caso Departamento de Administração e Economia (DAE); e, por fim, o nome da instituição.

\section{RESULTADOS E DISCUSSÃO}

Preliminarmente, através das médias e medidas de dispersão (desvio-padrão, mínimo e máximo), os escores por fator dos participantes foram sintetizados conforme Quadro 5. Dessa forma, a primeira observação a ser feita é que, em média, os servidores se percebem como bem socializados na maioria dos fatores mensurados, confirmado pelas baixas diferenças significativas entre as médias e levando-se em consideração os respectivos desvios-padrão. 
Quadro 5 Análises descritivas dos fatores do Inventário de Socialização Organizacional

\begin{tabular}{|c|c|c|c|c|c|c|c|}
\hline $\mathbf{N}^{\mathbf{0}}$ & Fatores do ISO & $\mathbf{N}$ & Mínimo & Máximo & Média & $\begin{array}{c}\text { Desvio- } \\
\text { padrão }\end{array}$ & $\begin{array}{c}\text { Alpha de } \\
\text { Cronbach }\end{array}$ \\
\hline 1 & $\begin{array}{c}\text { Acesso a Informações } \\
\text { (Políticas) }\end{array}$ & 289 & 1 & 5 & 3,76 & 0,93 &, 764 \\
\hline 2 & Competência e Proatividade & 289 & 1,30 & 5 & 4,35 & 0,66 &, 828 \\
\hline 3 & Integração com as Pessoas & 289 & 1 & 5 & 4,01 & 0,94 &, 835 \\
\hline 4 & $\begin{array}{c}\text { Não Integração com a } \\
\text { Organização }\end{array}$ & 289 & 1 & 5 & 4,37 & 0,89 &, 705 \\
\hline 5 & Qualificação Profissional & 289 & 1,33 & 5 & 4,41 & 0,70 &, 641 \\
\hline 6 & $\begin{array}{c}\text { Objetivos e Valores } \\
\text { Organizacionais }\end{array}$ & 289 & 1 & 5 & 4,11 & 0,80 &, 810 \\
\hline 7 & Linguagem e Tradição & 289 & 1 & 5 & 3,93 & 0,98 &, 778 \\
\hline
\end{tabular}

Fonte: dados da pesquisa.

Destacam-se positivamente os escores médios dos fatores: Qualificação Profissional (Média de 4,41), Não Integração com a Organização (Média de 4,37), Competência e Proatividade (Média de 4,35), Objetivos e Valores Organizacionais (Média de 4,11) e Integração com as Pessoas (Média 4,01), todos com médias entre 4,00 e 5,00. Contudo, quando se leva em consideração os desvios-padrão desses fatores, que também se apresentaram moderadamente baixos (máximo 0,94), percebe-se que existe certa população moderadamente socializada dentro da organização. Neste sentido destacam-se os fatores Integração com as Pessoas e Objetivos e Valores Organizacionais, ambos com escores próximos ao ponto neutro $(3,00)$.

Negativamente os escores médios dos fatores: Linguagem e Tradição (Média de 3,93) e Acesso a Informações (Políticas) (Média de 3,76). Este fato é agravado, e deve ser observado com atenção pelo departamento de Gestão de Pessoas da IFESP, pois os desviospadrão desses fatores estão entre os mais altos observados (0,98 e 0,93, respectivamente). Essas observações vêm a confirmar o que é apontado por Carvalho (2009). A autora expõe que informações relacionadas aos atributos organizacionais são menos importante para quem está iniciando, se comparado a outros aspectos do emprego.

Cabe observar, ainda, que o resultado do alpha de Cronbach desses fatores encontramse entre 0,641 e 0,835 , o que se constitui um resultado satisfatório, pois todos estão acima do ponto de corte aceito pelo Conselho Federal de Psicologia.

\subsection{VARIAÇÕES DO NÍVEL DE SOCIALIZAÇÃO ORGANIZACIONAL DOS SERVIDORES TÉCNICO-ADMINISTRATIVOS E DOCENTES}

A despeito do cargo (professor - técnico-administrativo), classe (adjunto, assistente, associado, EBTT, titular) e classificação (“A”, "B”, “C”, "D” e "E”), os dados referentes aos respondentes da pesquisa estão distribuídos conforme Gráfico 3. 
Gráfico 2 Cargo/Classe - Classificação

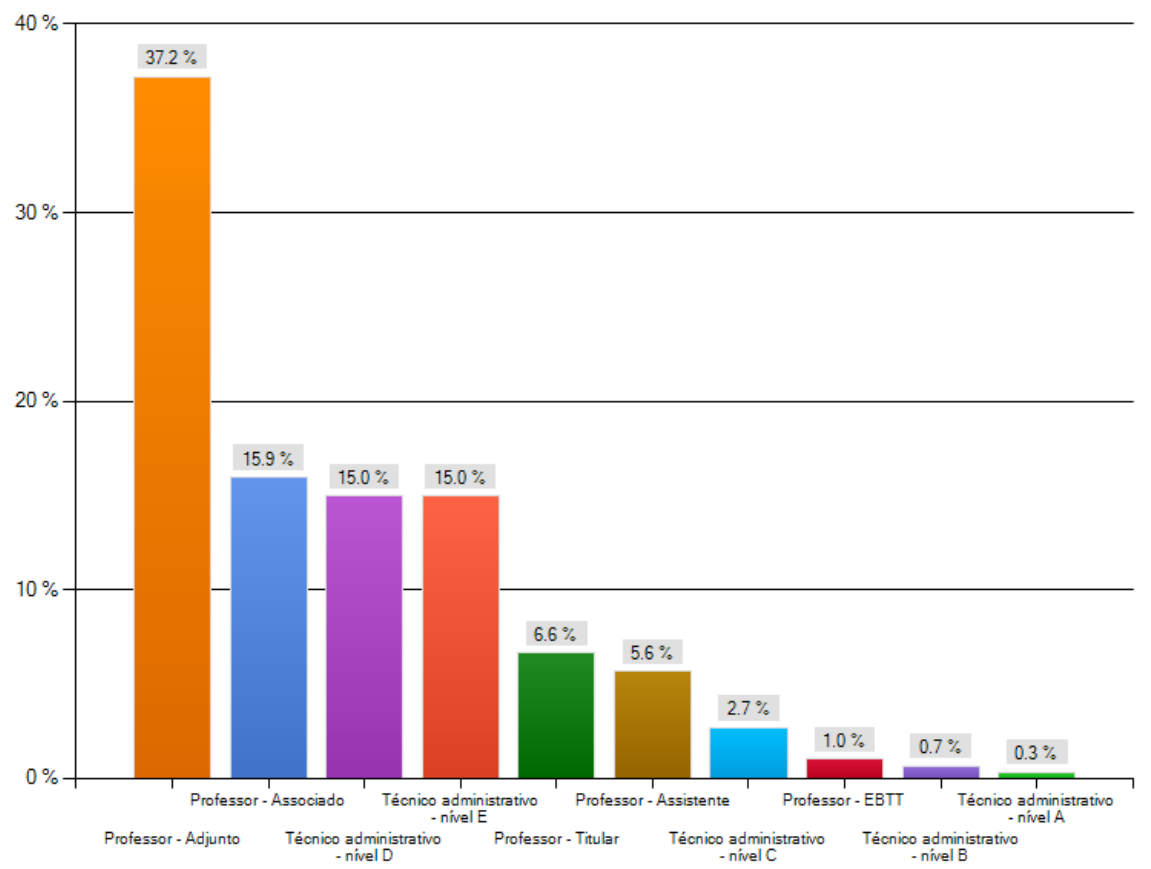

Fonte: dados da pesquisa

Assim, com base nos resultados de socialização no item anterior, e a divisão dos participantes em apenas dois grandes grupos (técnicos administrativos e docentes) aplicou-se o teste T de Student de maneira tal que se pudessem comparar os resultados encontrados aos dois cargos, conforme Quadro 7. 
Quadro 1 Estatísticas do Grupo

\begin{tabular}{|c|c|c|c|c|c|c|}
\hline $\mathbf{N}^{\mathbf{0}}$ & Fator da ISO & Grupo & $\mathbf{N}$ & Média & $\begin{array}{l}\text { Desvio- } \\
\text { Padrão }\end{array}$ & Teste $\mathbf{T}$ \\
\hline \multirow[t]{2}{*}{1} & \multirow{2}{*}{$\begin{array}{c}\text { Acesso a } \\
\text { Informações } \\
\text { (Políticas) }\end{array}$} & Docente & 196 & 3,3214 & 1,08781 & \multirow{2}{*}{$\begin{array}{c}\mathrm{T}=1,587 \\
\mathrm{gl}=289 \\
\mathrm{p}=, 588\end{array}$} \\
\hline & & $\begin{array}{c}\text { Técnicos } \\
\text { administrativos }\end{array}$ & 93 & 3,0968 & 1,19841 & \\
\hline \multirow[t]{2}{*}{2} & \multirow{2}{*}{$\begin{array}{l}\text { Competência e } \\
\text { Proatividade }\end{array}$} & Docente & 196 & 4,0153 & 0,70512 & \multirow{2}{*}{$\begin{array}{c}\mathrm{T}=1,533 \\
\mathrm{gl}=289 \\
\mathrm{p}=, 595\end{array}$} \\
\hline & & $\begin{array}{c}\text { Técnicos } \\
\text { administrativos }\end{array}$ & 93 & 4,1505 & 0,69072 & \\
\hline \multirow[t]{2}{*}{3} & \multirow{2}{*}{$\begin{array}{c}\text { Integração com as } \\
\text { Pessoas }\end{array}$} & Docente & 196 & 3,5459 & 1,01927 & \multirow{2}{*}{$\begin{array}{c}\mathrm{T}=-1,544 \\
\mathrm{gl}=289 \\
\mathrm{p}=, 624\end{array}$} \\
\hline & & $\begin{array}{c}\text { Técnicos } \\
\text { administrativos }\end{array}$ & 93 & 3,5699 & 1,02573 & \\
\hline \multirow[t]{2}{*}{4} & \multirow[b]{2}{*}{$\begin{array}{c}\text { Não Integração com } \\
\text { a Organização }\end{array}$} & Docente & 196 & 3,7500 & 0,97862 & \multirow{2}{*}{$\begin{array}{c}\mathrm{T}=-0,186 \\
\mathrm{gl}=289 \\
\mathrm{p}=, 563\end{array}$} \\
\hline & & $\begin{array}{c}\text { Técnicos } \\
\text { administrativos }\end{array}$ & 93 & 3,7204 & 1,01473 & \\
\hline \multirow[t]{2}{*}{5} & \multirow[b]{2}{*}{$\begin{array}{l}\text { Qualificação } \\
\text { Profissional }\end{array}$} & Docente & 196 & 4,1837 & 0,81457 & \multirow{2}{*}{$\begin{array}{c}\mathrm{T}=-0,237 \\
\mathrm{gl}=289 \\
\mathrm{p}=, 745\end{array}$} \\
\hline & & $\begin{array}{c}\text { Técnicos } \\
\text { administrativos }\end{array}$ & 93 & 4,2043 & 0,84131 & \\
\hline \multirow[t]{2}{*}{6} & \multirow{2}{*}{$\begin{array}{c}\text { Objetivos e Valores } \\
\text { Organizacionais }\end{array}$} & Docente & 196 & 3,9482 & 1,02957 & \multirow{2}{*}{$\begin{array}{c}\mathrm{T}=-0,199 \\
\mathrm{gl}=289 \\
\mathrm{p}=, 656\end{array}$} \\
\hline & & $\begin{array}{c}\text { Técnicos } \\
\text { administrativos }\end{array}$ & 93 & 3,6751 & 1,01354 & \\
\hline \multirow[t]{2}{*}{7} & \multirow[b]{2}{*}{$\begin{array}{l}\text { Linguagem e } \\
\text { Tradição }\end{array}$} & Docente & 196 & 3,8035 & 0,93631 & \multirow{2}{*}{$\begin{array}{c}\mathrm{T}=0,197 \\
\mathrm{gl}=289 \\
\mathrm{p}=, 010\end{array}$} \\
\hline & & $\begin{array}{c}\text { Técnicos } \\
\text { administrativos }\end{array}$ & 93 & 3,7413 & 0,98940 & \\
\hline
\end{tabular}

Fonte: dados da pesquisa

Percebeu-se que não há diferenças significativas ( $p>0,05)$ entre as médias apresentadas na maioria dos fatores hipotéticos. Dessa forma, ao se analisar as médias e desvios-padrão da comparação entre técnicos administrativos e professores, não se pode, de forma geral, afirmar que existem diferenças, uma vez que há heterogeneidade nos resultados dos fatores. O que corrobora as observações de Chao et al. (1994), que afirma que, normalmente, as pessoas bem socializadas em seus papéis organizacionais são dotadas de habilidades intrínsecas e independem de posição social.

A única exceção é encontrada no fator Linguagem e Tradição com ( $\mathrm{p}=0)$, que corroboram a indicação inicial de boa socialização na instituição (cálculos das médias e medidas de dispersão), independentemente do grupo ocupacional.

\subsection{VARIAÇÕES DO NÍVEL DE SOCIALIZAÇÃO ORGANIZACIONAL DOS SERVIDORES QUANTO À LOTAÇÃO SETORIAL/DEPARTAMENTAL}

$\mathrm{Na}$ tentativa de observar se o nível de socialização varia de acordo com o setor/departamento no qual o servidor executa suas atividades laborais, buscou-se, mediante análise de cluster, separá-los pelos diferentes perfis, através da elaboração do dendograma. 
Assim, diante do resultado da árvore de classificação (ou dendograma), optou-se por percorrer a partir da raiz (Dlink/Dmax $=1.0)$ em direção às folhas e parar em Dlink/Dmax = 8.0. Essa ação resultou em três instâncias distintas, dadas cada qual pelo seu ramo correspondente e nível de socialização.

De acordo com essas instâncias, alocaram-se os respondentes separados pelo seu setor/departamento, com o intuito de balizar e aferir os resultados, em: Grupo 1 - mais socializado; Grupo 2 - médio socializado; e Grupo 3 - menos socializado; então, distribuíramse três pontos, dois pontos e um ponto, respectivamente.

Para a análise, com base nos resultados observados, dividiu-se em três diferentes conjuntos, levando-se em consideração o número de respondentes por setor/departamento, da seguinte forma: Conjunto A - até 10 respostas por setor/departamento; Conjunto B - entre 10 e 20 respostas por setor/departamento; e, Conjunto C - com mais de 20 respostas por setor/departamento.

Dessa maneira, no Conjunto A com os maiores escores (100), observaram-se os seguintes setores: Coordenadoria de Cerimonial (Ascer), Prefeitura, Procuradoria, Serviço Orgânico de Segurança Patrimonial (Sops) e Transporte. Contudo, cabe ressaltar que à exceção da Prefeitura, que se aferiram duas respostas, os outros setores tiveram apenas uma participação, o que enfraquece o resultado.

No Conjunto B (entre 10 e 20 respostas), o Departamento de Ciências Exatas (DEX), com 14 respostas e resultado final de 80,95, mostraram-se com alto nível de socialização organizacional. Também se destacou positivamente o Departamento de Ciência dos Alimentos (DCA), com 17 respostas e resultado final de 76,47.

No terceiro e último Conjunto (mais de 20 respostas), 27 observações foram aferidas nos seguintes departamentos: Departamento de Medicina Veterinária (DMV) 69,14 e Departamento de Administração e Economia (DAE) 61,73.

Conclusivamente, a análise de cluster considerando esses três perfis, ou níveis de socialização distintos apresentou-se heterogêneo, e os resultados do dendograma e do quadro balizador de cada cluster não permitiram a identificação com precisão do setores/departamentos com maior ou menor nível de socialização de forma satisfatória; esses evidenciados, ainda mais, a partir do baixo número de respostas. Ademais, os resultados confirmam os aspectos apontados sobre a afirmação de Van Maanen (1989) a despeito da atmosfera informal de socialização. Mas, ao mesmo tempo, corrobora a indicação inicial de eficácia da socialização na Instituição, se levado em consideração o resultado final total de 74,08 pontos, quando pontuadas as possibilidades dos três grupos juntos (285 dividido pela soma dos pontos Grupo 1, Grupo 2 e Grupo 3, vezes 100).

\section{CONSIDERAÇÕES FINAIS}

No presente trabalho propõem-se examinar o nível de socialização organizacional em uma Instituição Federal de Ensino Superior, segundo os grupos ocupacionais docentes e técnico-administrativos, buscando avaliar se há entre estes servidores diferenças no nível de socialização organizacional. E, ainda, diante de um entendimento mais amplo acerca do 
fenômeno, procurou-se observar se o nível de socialização organizacional varia quanto à lotação setorial/departamental.

Para alcançar esses propósitos, utilizou-se um Inventario de Socialização Organizacional, composto de 45 itens, validado ao setor público brasileiro. Cabendo ressaltar, ainda, que o período de coleta de dados da pesquisa ocorreu entre os dias 12 de abril e 27 de julho de 2011.

Assim, o estudo empreendido possibilitou algumas observações relevantes. A primeira delas refere-se ao fato de que há uma tendência geral a uma socialização eficaz na Instituição, frente às médias obtidas para os fatores mensurados e os diferentes perfis, com destaque aos fatores hipotéticos: Competência e Proatividade, Integração com as Pessoas, Não Integração com a Organização, Qualificação Profissional, Objetivos e Valores Organizacionais. Essas conclusões já negam a hipótese inicial do trabalho, não obstante haja as diferenças significativas nos fatores Acesso a Informações (Políticas) e Linguagem e Tradição, merecedores de atenção por parte dos gestores, pois ambos apresentaram escores baixos. Desses, o fator Acesso a Informações (Políticas) destaca-se ainda mais negativamente, por apresentar desvio-padrão elevado e pelo seu baixo escore.

No que se refere às diferenças existentes entre servidores técnico-administrativos e docentes no nível de socialização, conclui-se que, de forma geral, há heterogeneidade nos resultados dos fatores. Corroborando, portanto, a indicação inicial de eficácia da socialização na instituição, independentemente do grupo ocupacional. Ademais, um fator que chamou a atenção foi o denominado Linguagem e Tradição, que apresentou diferença significativa, se comparado aos resultados apresentados nos demais fatores. $\mathrm{O}$ fato pode ser compreendido se levado em consideração que os técnicos administrativos possuem de maneira geral uma formação não condizente ou ampla à sua função. A exemplo de um concurso para técnico administrativo nível " $D$ ", que a exigência de escolaridade é nível médio, e ao tomar posse, esse servidor poderá trabalhar na biblioteca da instituição, na secretária de um laboratório de solos, de veterinária ou de um departamento, como o de administração, ou seja, são diferentes situações e linguagens para uma formação "padrão". Esse problema pode ser agravado se levado em consideração o fato do grande número de vagas ofertadas em um único concurso, o que impossibilita a chance de estratificação de perfis com conhecimentos mais específicos, mesmo dentro de uma mesma formação.

A despeito da identificação do setor ou departamento com maior ou menor nível de socialização, cabe ressaltar que essa tentativa mostrou-se inválida, uma vez que não foi possível afirmar que há na Instituição um local onde os servidores possuem um nível mais ou menos socializado com precisão. Sobre esse fato, pode-se concluir que o processo de socialização ocorre na instituição de forma natural e homogênea, não sendo possível afirmar que, caso ocorra, alguma ação socializante motivada por ações especificas - por exemplo, tutorização, integração, etc. (VAN MAANEN, 1989) - em certo departamento ou setor, estejam trazendo benefícios ou impactos positivos sobre os servidores. Cabe ainda pontuar que esse resultado também corrobora a afirmação de que, de uma maneira geral, a instituição se encontra em um elevado nível de socialização organizacional.

Conclusivamente, esta pesquisa aponta que o momento de expansão pelo qual passa a Universidade do estudo pode ser frutífero, com tendências de bom aproveitamento do seu 
quadro permanente, levando-se em consideração os níveis de socialização. É sabido que esta não é a única forma de se medir a eficiência de uma instituição; contudo, é um indicativo plausível e ainda pouco estudado e aplicado no Brasil. Lembrando que, especificamente no caso da IFES, alguns índices ainda podem ser melhorados pelo departamento de Gestão de Pessoas, por meio de estratégias de socialização, como apontados anteriormente no trabalho.

Como limite do trabalho, têm-se problemas típicos aos métodos quantitativos, e seus resultados amplos e horizontalizados (PASQUALI, 2003) e o baixo número de respondentes que impossibilitou um resultado eficiente diante da análise de cluster. Ainda, vislumbram-se investigações que incluam a utilização de métodos de pesquisa qualitativos, com o intuito de se aprofundar os conhecimentos em torno dos fenômenos de Socialização Organizacional. Além disso, sugere-se a realização de novos trabalhos com o ISO, inclusive uma nova aferição fatorial e/ou análise confirmatória através do método de equações estruturais, a fim de possibilitar ao Inventário tornar-se um instrumento de gestão amplamente utilizado e fiável.

\section{Notas}

1. Por questões éticas, os autores optaram por manter o anonimato da Instituição pesquisada. 


\section{REFERÊNCIAS}

ANDRADE, D. C. T. ; CASTRO, C. G. ; CAPPELlE, M. C. A. ; PEREIRA, J. R. . A Gestão Pública e o REUNI: entre o Social e o Gerencial. Revista da Universidade Vale do Rio Verde, v. 9, p. 154$170,2011$.

ASHFORTH, B. E. et al. Socialization tactics, proactive behavior, and newcomer learning: Integrating socialization models. Journal of Vocational Behavior, Orlando, v. 70, n. 3, p. 447-462, June 2007.

BAGOZZI, R. P.; YI, Y.; PHILIPPS, L. W. Assessing construct validity in organizational research. Administrative Science Quarterly, Ithaca, v. 36, n. 3, p. 421-458, Sept. 1991.

BERGER, P. L.; BERGER, B. Socialização: como ser um membro da sociedade. In: FORACHI, M.; MARTINS, J. S. (Org.). Conceitos sociológicos fundamentais. Rio de Janeiro: LTC, 1977. p. 200214.

BERGER, P. L.; LUCKMANN, T. A sociedade como realidade subjetiva. In: BERGER, P. L.; LUCKMANN, T. A construção social da realidade. Petrópolis: Vozes, 1985. p. 173-228.

BERGER, P. L.; LUCKMANN, T. Modernidade, pluralismo e crise de sentido: a orientação do homem Moderno. Petrópolis: Vozes, 2004.

BORGES, L. O. et al. Re-construção e validação de um inventário de socialização organizacional. Revista de Administração Mackenzie, São Paulo, v. 11, n. 4, p. 4-37, jul./ago. 2010.

BRASIL. Decreto $\mathbf{n}^{\mathbf{0}}$ 6.096, de 24 de abril de 2007. Institui o Programa de Apoio a Planos de Reestruturação e Expansão das Universidades Federais - REUNI. Disponível em: <http://www.planalto.gov.br/ccivil_03/_Ato2007-2010/2007/Decreto/D6096.htm>. Acesso em: 10 dez. 2009a.

BRESSER-PEREIRA, L. C. Do estado patrimonial ao gerencial. In: SACHS, I.; WILHEIM, J.; PINHEIRO, P. S. (Ed.). Brasil: um século de transformações. São Paulo: Companhia das Letras, 2001. p. 222-259.

CARVALHO, V. D. Resiliência e socialização organizacional de novos servidores: um estudo transcultural. 2009. 272 p.Tese (Doutorado em Psicologia Social) - Universidade Federal do Rio Grande do Norte, Natal, 2009.

CERVO, A. L.; BERVIAN, P. A. Metodologia científica. 4. ed. São Paulo: Makron Books, 1996. 242 p.

CHANLAT, J. F. et al. O indivíduo na organização: dimensões esquecidas. São Paulo: Atlas, 1996. $204 \mathrm{p}$. 
CHAO, G. T. et al. Organizational socialization: its content and consequences. Journal of Applied Psychology, Washington, v. 79, n. 5, p. 730-743, Oct. 1994.

COCHRAN, W. G. Sampling techniques. New York: J. Wiley, 1965. 413 p.

DURKHEIM, E. As regras do método sociológico as regras do método sociológico as regras do método sociológico. São Paulo: Companhia Editora Nacional, 1987. 1285 p.

FELDMAN, D. C. A contingency theory of socialization. Administrative Science Quarterly, Ithaca, v. 21, n. 3, p. 433-450, 1976.

GÜNTHER, H. Como elaborar um questionário. In: PASQUALI. L. (Org.). Instrumentos psicológicos: manual prático de elaboração. Brasília: LabPAM IBAPP, 1999. p. 231-258.

HAUETER, J. A.; MACAN, T. H.; WINTER, J. Measurement of newcomer socialization: construct validation of a multidimensional scale. Journal of Vocational Behavior, Orlando, v. 63, n. 1, p. 20 39, Aug. 2003.

INSTITUIÇÃO FEDERAL DE ENSINO SUPERIOR PESQUISADA. Reuni. Disponível em: < http://www.nomedainstituicao.br/ >. Acesso em: 10 mar. 2011.

LAKATOS, E. M.; MARCONI, M. A. Técnicas de pesquisa: planejamento e execução de pesquisas, elaboração, análise e interpretação dos dados. 4. ed. São Paulo: Atlas, 1995. 206 p.

LÉDA, D.; MANCEBO, D. REUNI: heteronomia e precarização da universidade e do trabalho docente. Educação \& Realidade, Porto Alegre, v. 34, n. 1, p. 49-64, jan./abr. 2009.

LEVY JUNIOR, M. Socialização. In: CARDOSO, F. H.; IANNI, O. (Org.). Homem sociedade. São Paulo: Editora Nacional, 1973. 318 p.

MARINI, C. O contexto contemporâneo da gestão pública na América Latina. Revista do Servidor Público, Brasília, v. 53, n. 4, p.31-52, out./dez. 2002.

MARTIN-BARÓ, I. Los procesos de socialización. In: MARTIN-BARÓ, I. Acción e ideología: psicología social desde Centroamérica. El Salvador: UCA Editores, 1992. p. 113-180.

MARTINS, J. de S. A exclusão social e a nova desigualdade. São Paulo: Paulus, 1997. 140 p.

MATTAR, F. N. Pesquisa de marketing: metodologia, planejamento. 5. ed. São Paulo: Atlas, 1999. $314 \mathrm{p}$. 
MENDES, V. L. P. S.; TEIXEIRA, F. L. O novo gerencialismo e os desafios para a administração pública. In: ENCONTRO DA ASSOCIAÇÃO NACIONAL DOS PROGRAMAS DE PÓS GRADUAÇÃO EM ADMINISTRAÇÃO, 24., 2000, Florianópolis. Anais... Florianópolis: ANPAD, 2000. 1 CD-ROM.

MORRISON, E. W. Information usefulness and acquisition during organizational encounter. Management Communication Quarterly, New York, v. 9, n. 2, p. 131-155, Nov. 1995.

MOTTA, F. C. P. Controle social nas organizações. Revista de Administração de Empresas, São Paulo, v. 33, n. 5, p. 68-87, set./out. 1993.

OLIVEIRA, S. D. C. et al. A socialização organizacional dos servidores da UFRN, segundo grupo ocupacional e tempo de serviço. Revista Psicologia, Florianópolis, v. 8, n. 1, p. 118-141, 2008.

OSTROFF, C.; KOZLOWSKI, S. W. J. Organizational socialization: the role of information acquisition. Personnel Psychology, Washington, v. 45, n. 4, p. 849-872, Dec. 1992.

PASQUALI, L. Psicometria: teoria e aplicações. Brasília: UnB, 1997.

PASQUALI, L.. Testes referentes a construto: teoria e modelo de construção. In: PASQUALI, L.. (Org.). Instrumentos psicológicos: manual prático de elaboração. Brasília: LabPAM Ibapp, 1999. p. 27-36.

PASQUALI, L. Psicometria: teoria dos testes na psicologia e na educação. Petrópolis: Vozes, 2003. $400 \mathrm{p}$.

SCHEIN, E. H. A psicologia organizacional. Rio de Janeiro: Prentice-Hall, 1982. 224 p.

SHINYASHIKI, G. T. O processo da socialização organizacional. In: FLEURY, M. T. As pessoas na organização. São Paulo: Gente, 2003. p. 165-184.

TAORMINA, R. J. Organizational socialization: a multidomain, continuous process models. International Journal of Selection and Assessment, New York, v. 5, n. 1, p. 29-47, Jan. 1997.

TORREGROSA, J. R.; VILLANUEVA, C. F. La interiorización de la estrutura social. In: TORREGROSA, J. R. Y.; CRESPO, E. Estudos básicos de psicologia social. Barcelona: Hora, 1984. p. 421-446.

UNIVERSIDADE FEDERAL DA BAHIA. Universidade nova: reestruturação da arquitetura acadêmica da UFBA. Salvador, 2007. Disponível em: <http://www2.faced.ufba.br/noticias/noticias/universidadenova25102006>. Acesso em: 10 dez. 2009. 
VAN MAANEN, J. Processando as pessoas - estratégias de socialização organizacional. In: FLEURY, M. T. L.; FISCHER, R. M. Cultura e poder nas organizações. São Paulo: Atlas, 1989. cap. 2, p. 4562. 